Original Article

\title{
The prevalence of the flat foot condition and insole prescription in people with Down's syndrome: a retrospective population-based study
}

\author{
Yoshinide Kanai, RPT, $\mathrm{PhD}^{1)^{*}}$, Hirotaka MutsuZaki, MD, PhD²), \\ Tomohiro Nakayama, MD, $\mathrm{PhD}^{3)}$, Arito Yozu, MD, $\mathrm{PhD}^{4)}$, Nobuaki Iwasaki, MD, PhD ${ }^{3)}$ \\ 1) Department of Physical Therapy, Ibaraki Prefectural University of Health Sciences: 4669-2 Ami- \\ machi Ami, Inashiki-gun, Ibaraki 300-0394, Japan \\ 2) Department of Orthopaedic Surgery, Ibaraki Prefectural University of Health Sciences, Japan \\ 3) Department of Paediatrics, Ibaraki Prefectural University of Health Sciences, Japan \\ 4) Department of Rehabilitation Medicine, Ibaraki Prefectural University of Health Sciences, Japan
}

\begin{abstract}
Purpose] The general approach for flat foot (FF) treatment in people with Down's syndrome (DS) is the use of insoles. However, the appropriate timing of the first insole prescription remains unclear. An aim of this present research was to investigate the status of prevalence of FF and orthosis prescription in the DS population. [Subjects and Methods] Two hundred fifteen subjects with DS who were seen at our hospital were retrospectively investigated. Investigated parameters were: prevalence of FF and other foot diseases, ratio and timing of orthopaedic consultation, ratio and timing of orthoses prescription, and mean age at the time of orthosis prescription. [Results] The prevalence of FF was $27.0 \%$ (58 subjects), and 50 subjects (23.3\%) consulted an orthopaedic surgeon. An orthosis was prescribed for 54 subjects; $88.9 \%$ of these orthoses were insoles. Foot and leg orthoses other than insoles were prescribed significantly more frequently for females than males. The mean ages at the time of the first prescription of all types of orthoses and an insole were 7.3 years and 6.4 years, respectively. [Conclusion] The prevalence of FF was low, and the age at which subjects with DS were prescribed an orthosis was relatively high at our institution compared to previous reports. Since physical therapists see patients who could potentially have FF, those with suspected FF should then be referred to an orthopaedic doctor, which would enable the earlier orthosis prescription.

Key words: Down's syndrome, Flat foot, Insole
\end{abstract}

(This article was submitted Dec. 5, 2017, and was accepted Jan. 9, 2018)

\section{INTRODUCTION}

The prevalence of Down's syndrome (DS) was estimated as 8.27 people with DS per 10,000 population in the period from 2006-2007 in the United States ${ }^{1)}$, and 11.1 people with DS per 10,000 population in 2015 in the Netherlands ${ }^{2)}$. The Dutch DS prevalence is gradually increasing because of an increase in maternal age ${ }^{2)}$; this situation is likely to be similar in other advanced countries. To extend the life expectancy in the DS population, efforts are needed in the fields of anti-aging and prevention of fragility. The DS population will be affected by advancing age and will develop secondary problems such as Alzheimer's disease and dementia ${ }^{3,4}$. The symptoms of people with DS are varied, but include the following: congenital heart defects, thyroid disease, cognitive impairment, seizures, hypotonus, and delays in both gross and fine motor

*Corresponding author. Yoshihide Kanai (E-mail: kanai@ipu.ac.jp)

(C2018 The Society of Physical Therapy Science. Published by IPEC Inc.

(c) (1) $\odot$ This is an open-access article distributed under the terms of the Creative Commons Attribution Non-Commercial No Deriva-

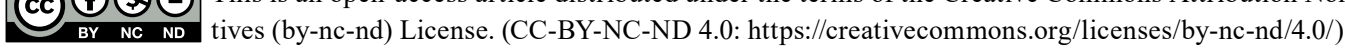


development ${ }^{5,6)}$. People with DS also frequently have orthopaedic complications such as hip dislocation, scoliosis, and upper cervical spine instability ${ }^{7-9}$.

One well-known orthopaedic problem in the DS population is flat foot $(\mathrm{FF})^{9,}{ }^{9}$. There is a correlation between the emergence of FF and joint laxity ${ }^{11)}$, and joint laxity is reportedly present in $76.5 \%$ of children with $\mathrm{DS}^{12}$ ). FF causes extra rotation of the foot and alters the gait pattern ${ }^{13)}$. The general approach for FF treatment is the use of insoles, which is an important part of physical therapy. Previous studies have recommended that persons with DS use an insole ${ }^{13}$, 14). However, the appropriate timing of the first insole prescription remains unclear, despite one report investigating the effect of timing ${ }^{15)}$. The aim of the present study was to investigate the current status of our institution regarding prevalence of FF and orthosis prescription (especially insoles) in the DS population, and to discuss the timing for insole prescription.

\section{SUBJECTS AND METHODS}

All people with DS who consulted a medical doctor at Ibaraki Prefectural University Hospital from August, 2008 to May, 2017 were included in the present retrospective, population-based study. This study was approved by the Ibaraki Prefectural University of Health Sciences Ethics Committee (approval no. 778), and endorsed by the Research Ethics Committee at Ibaraki Prefectural University of Health Sciences Hospital. We adopted an opt-out style for maintaining the right for subjects to end the participation in the study whenever they hoped.

Data were collected for the following variables: (1) gender, (2) age, (3) number of subjects diagnosed with FF, (4) number of subjects diagnosed with foot diseases other than FF, and (5) number of subjects who had an orthopaedic consultation. Data collected regarding orthoses for lower extremities included: (6) number of subjects who were prescribed orthoses, (7) mean number of times an orthosis was prescribed, (8) type of first orthosis prescribed, and (9) number of subjects diagnosed with FF who were prescribed an insole.

Other evaluated parameters were: (10) mean follow-up duration from the first date an orthosis was made to the latest date that the subject had a consultation with a medical doctor (until May 2017), (11) mean age of subjects at the time of their first orthosis prescription, (12) mean age of subjects prescribed an insole as a first orthosis, (13) mean age of subjects aged less than 10 years who were prescribed an insole as a first orthosis, and (14) mean intervals between insole prescription renewals. As some subjects with DS waited a long time before deciding to use an insole, some of the subjects were adults before they received their first insole prescription, instead of obtaining an insole at the time at which they started to walk during natural motor development. Therefore, in order to exclude those subjects who started using an orthosis after reaching adulthood, we also calculated the mean age of patients who started using an insole before the age of 10 years.

Descriptive statistics were calculated for the study population. To compare the differences between males and females, non-paired t-tests were conducted to assess the following: (2), (10), (11), (12), (13), and (14). The Mann-Whitney U test was used to evaluate (7). The $\chi^{2}$ test was used to assess the following parameters: (3), (4), (5), (6), (8), and (9). Statistical analyses were done using SPSS Statistics ver. 24 (IBM SPSS, IBM Corp., NY, USA). The level of statistical significance was set at $\mathrm{p}=0.05$.

\section{RESULTS}

The characteristics of the subjects with DS are detailed in Table 1. A total of 216 people with DS were included in this study. One female died before study completion, and so her data was excluded. Of the 215 people with DS who visited our hospital, 58 were diagnosed with FF, and 11 were diagnosed with the following other foot diseases: foot deformity ( $\mathrm{n}=2)$, hallux valgus $(n=3)$, equinus foot $(n=1)$, spread foot $(n=1)$, pes varus $(n=2)$, callus $(n=1)$, and pes cavus $(n=1)$. A total of 50 subjects consulted an orthopaedic surgeon. These parameters indicated no significant difference between genders.

The data regarding items involving orthoses are listed in Table 2. An insole was prescribed for 47 of the 58 patients diagnosed with FF. An orthosis for a lower extremity was prescribed for 54 of 215 subjects, and each subject was prescribed an orthosis for a lower extremity a mean of 2.3 times. The type of first orthosis for a lower extremity was classified as either an insole or other foot or leg orthosis. In our institution, foot and leg orthoses other than an insole were prescribed significantly more frequently in female subjects than in males $(\mathrm{p}<0.05)$. Regarding other types of orthoses other than an insole, one male patient was prescribed a shoe-type orthosis, while the orthoses prescribed for female subjects included an ankle-foot orthosis $(n=2)$, a plastic ankle-foot orthosis $(n=1)$, and a knee brace $(n=2)$. An insole was prescribed as the first orthosis in 48 of 54 subjects. The mean follow-up duration was 3.0 years in all subjects, 3.1 years in males, and 2.8 years in females. These parameters excluding other type of foot or leg orthosis showed no significant difference between genders.

The temporal parameters involving orthosis prescription are shown in Table 3 . The mean age of subjects when they were first prescribed an orthosis was 7.3 years in the 54 subjects who were prescribed an orthosis, and 6.4 years in the 48 subjects who were prescribed an insole as a first orthosis. The mean age of subjects who were first prescribed an orthosis before they were 10 years of age was 4.0 years for both genders. The mean interval between insole prescription renewals was 1.2 years in all subjects, and was also 1.2 years for each gender. These parameters indicated no significant difference between genders. 


\section{DISCUSSION}

In the present study, $25.4 \%$ of males with DS and $29.0 \%$ of females with DS were diagnosed with FF. In our institution, the mean prevalence of FF in both genders with DS was $27.0 \%$, and the percentage of subjects who had a consultation with an orthopaedic surgeon was $23.3 \%$. Previous studies have reported an FF prevalence in subjects with DS of $60 \%{ }^{16)}$ and $83 \%{ }^{17)}$; hence, the FF prevalence detected in our study was considerably low. Therefore, FF may have been missed in a lot of subjects with DS, as although only $23.3 \%$ of people with DS visited an orthopaedic department in our institution, almost all of the subjects diagnosed with FF who once consulted an orthopaedic surgeon were prescribed an orthotic by the doctor. The low prevalence of FF in our study was possibly associated with a low ratio of consulting with an orthopaedic surgeon. If more patients with DS visited an orthopaedic department at an adequate timing, a ratio of detection for FF would have got higher and some kind of orthosis would have been prescribed. Indeed, 54 of 58 subjects diagnosed with FF were prescribed some type of orthosis, and 47 of these orthoses were insoles. This may indicate that an insole was adequately prescribed to subjects

Table 1. Characteristics of subjects with Down's syndrome

\begin{tabular}{lccc}
\hline & Total & Male & Female \\
\hline Gender (n) & 215 & 122 & 93 \\
Age (years) & $14.2 \pm 8.9$ & $14.0 \pm 8.6$ & $14.5 \pm 9.3$ \\
Diagnosis of flat foot (n; of 215 patients) & 58 & 31 & 27 \\
Prevalence of flat foot (\%) & 27.0 & 25.4 & 29.0 \\
Diagnoses of foot diseases other than flat foot (n; of 215 patients) & 11 & 5 & 6 \\
Prevalence of other foot diseases (\%) & 5.1 & 4.1 & 6.5 \\
Subjects who consulted an orthopaedic surgeon (n; of 215 patients) & 50 & 23 & 27 \\
$\quad$ Ratio (\%) & 23.3 & 18.9 & 29.0 \\
\hline
\end{tabular}

Values are shown as mean $\pm \mathrm{SD}$.

Table 2. Orthotic data from the subjects with Down's syndrome

\begin{tabular}{|c|c|c|c|c|}
\hline & & Total & Male & Female \\
\hline Subjects who were prescribed an orthosis (n) & & 54 & 28 & 26 \\
\hline Mean number of times an orthosis for lower extremity was prescribed & & $2.3 \pm 1.5$ & $2.5 \pm 1.6$ & $2.0 \pm 1.3$ \\
\hline \multicolumn{5}{|l|}{ Type of first orthosis for lower extremity } \\
\hline Insole (of 54 patients) & & 48 & 27 & 21 \\
\hline Ratio (\%) & & 88.9 & 96.4 & 80.8 \\
\hline Other type of foot or leg orthosis (of 54 patients) & & 6 & 1 & $5^{*}$ \\
\hline Ratio (\%) & & 11.1 & 3.6 & 19.2 \\
\hline Subjects diagnosed with FF who were prescribed an insole (n) & & 47 & 27 & 20 \\
\hline Ratio (\%; $\mathrm{n}=47$ of 58 who were diagnosed with $\mathrm{FF})$ & & 87.0 & 96.4 & 76.9 \\
\hline \multicolumn{2}{|c|}{$\begin{array}{l}\text { Mean follow-up duration from the first date an orthosis was made to the latest date of consultation } \\
\text { with a medical doctor (until May, 2017) (years; } n=54: 28 \text { males and } 26 \text { females) }\end{array}$} & $3.0 \pm 2.1$ & $3.1 \pm 2.2$ & $2.8 \pm 2.0$ \\
\hline \multicolumn{5}{|c|}{$\begin{array}{l}\text { Values are shown as mean } \pm \mathrm{SD} \\
\text { FF: flat foot. } \\
{ }^{*} \mathrm{p}<0.05\end{array}$} \\
\hline & Total & $\mathrm{Mal}$ & & Female \\
\hline Mean age of subjects at the time of first orthosis prescription (years; $n=54$ ) & $7.3 \pm 7.0$ & $6.1 \pm$ & & $8.6 \pm 8.6$ \\
\hline Mean age of subjects prescribed an insole as a first orthosis (years; $n=48$ ) & $6.4 \pm 5.5$ & $6.2 \pm$ & & $6.7 \pm 6.2$ \\
\hline $\begin{array}{l}\text { Mean age of subjects aged less than } 10 \text { years who were prescribed an insole as a } \\
\text { first orthosis (years; } n=38: 22 \text { males and } 16 \text { females) }\end{array}$ & $4.0 \pm 1.5$ & $4.0 \pm$ & & $3.9 \pm 1.5$ \\
\hline $\begin{array}{l}\text { Mean interval between repeat insole prescriptions (years) }\left(\mathrm{n}=58^{\mathrm{a}}: 36 \text { males and }\right. \\
22 \text { females) }\end{array}$ & $1.2 \pm 0.6$ & $1.2 \pm$ & & $1.2 \pm 0.4$ \\
\hline
\end{tabular}

Values are shown as mean \pm SD.

aTotal number of persons who were prescribed an insole multiple times. 
with DS who potentially had FF and/or to those who needed to use an insole because they had consulted with an orthopaedic surgeon. Physical therapists also see patients who could potentially have FF, and should therefore evaluate the feet in detail during the physical therapy session; those with suspected FF could then be referred to an orthopaedic doctor, which would enable the earlier orthosis prescription.

In the present study, the frequency of orthosis prescription in subjects with DS did not significantly differ between genders. Although an orthosis other than an insole was prescribed significantly more frequently for females than for males, there was no significant difference between the genders in the prevalence of FF or other foot diseases. Previous studies have reported that most healthy patients with FF are female, and that FF occurs due to a variety of reasons ${ }^{18)}$. In our research, although the prevalence of foot diseases was similar between genders, the severity of foot diseases in females may have been more severe than that in males, and this may be the reason that orthoses other than insoles were prescribed more often for females than males. As the present research was a retrospective population-based study, the details of the foot conditions were not clarified.

The mean age of subjects with DS at the time that they were prescribed their first orthosis was 7.3 years, and the mean age of subjects with DS who were prescribed an insole as a first orthosis was 6.4 years. The mean age of the subjects aged less than 10 years when they were prescribed an insole as a first orthosis was 4.0 years. A previous study reported that the mean age at which children with DS started an independent gait was 2.6 years ${ }^{19)}$, while another study stated that $92 \%$ of children with DS were able to walk at 3 years old ${ }^{20)}$. Thus, in our study, subjects with DS were older at the time of their first insole prescription than the average age at which most children with DS begin to walk (2.6-3.0 years). A Japanese study reported that the median timing of the first insole prescription for subjects with DS was 31 months in that institution ${ }^{15}$ ), which approximately corresponds to the onset of gait at 2.6 years of age ${ }^{19}$. At our institution, the age at first insole prescription was 6.4 years in the 48 total subjects and 4.0 years in those aged less than 10 years, which are both older than 31 months (2.6 years). This may be because the age at which subjects with DS visited our hospital was older than at the other institution, or there may have been a long interval between the time of first presentation at our hospital and consultation with an orthopaedic surgeon. Foot deformity caused by FF or other similar foot diseases could worsen and lead to a severe secondary disability; hence, subjects with DS should be assessed by an orthopaedic surgeon soon after gait commencement. In the present study, the average interval between insole prescription renewals was 1.2 years. We generally make a new insole at the time at which the feet have become too large for the current shoes and insoles, and a 1.2 year interval is regarded as appropriate considering the normal growth velocity. Therefore, the issue that we need to clarify is the appropriate age at which subjects with DS should be prescribed their first orthosis. The distinct reason why the age at first prescription in our study was later than that reported in previous studies is an important issue that needs to be further investigated.

We believe that it is important to use an insole that maintains the appropriate structure and the function of the foot, even if a stable and permanent arch is not shaped with the development of the muscle and the bone on the bottom of the foot. A previous study reported that $14.6-22.2 \%$ of subjects achieved longitudinal arch formation on their sole through treatments such as insole usage plus advice on the most appropriate kind of shoes ${ }^{14)}$; this means that about $70-80 \%$ of subjects with DS did not develop a longitudinal arch despite these treatment methods. FF may lead to less efficient walking and a less functional gait pattern ${ }^{21}$. Therefore, subjects with DS should use an insole, even if a longitudinal arch is not formed with the use of the orthosis, and should continue to renew their insole prescription throughout their life in order to maintain ambulatory ability. The effectiveness of orthoses other than insoles needs further clarification to provide information to medical workers, and to subjects with DS and their families.

The present study had some limitations. We could not discuss the severity of FF and the influence of insole usage on the posture and movement of the subjects with DS, as the present research was a retrospective population-based study. Furthermore, there was a bias in the number of subjects in each group and there was a small number of subjects in certain groups. However, the present study is the first step in defining the support needed for people with DS throughout their lives. People with DS require an insole prescription in the early stage of life, and further research is required to determine the appropriate timing for the first prescription of insoles for people with DS.

\section{Funding}

This work was supported by Grant-in-Aid for Community Research 2017 from Ibaraki Prefectural University of Health Sciences.

\section{Conflict of interest}

The authors have no conflicts of interest directly relevant to the content of this article.

\section{REFERENCES}

1) Presson AP, Partyka G, Jensen KM, et al.: Current estimate of Down Syndrome population prevalence in the United States. J Pediatr, 2013, 163: 1163-1168. [Medline] [CrossRef]

2) de Graaf G, Engelen JJ, Gijsbers AC, et al.: Estimates of live birth prevalence of children with Down syndrome in the period 1991-2015 in the Netherlands. J Intellect Disabil Res, 2017, 61: 461-470. [Medline] [CrossRef] 
3) Kozma C: Down syndrome and dementia. Top Geriatr Rehabil, 2008, 24: 41-53. [CrossRef]

4) Das JP, Divis B, Alexander J, et al.: Cognitive decline due to aging among persons with Down syndrome. Res Dev Disabil, 1995, 16: 461-478. [Medline] [CrossRef]

5) Bull MJ Committee on Genetics: health supervision for children with Down syndrome. Pediatrics, 2011, 128: 393-406. [Medline] [CrossRef]

6) Malak R, Kostiukow A, Krawczyk-Wasielewska A, et al.: Delays in motor development in children with Down syndrome. Med Sci Monit, 2015, 21: 1904-1910. [Medline] [CrossRef]

7) Mik G, Gholve PA, Scher DM, et al.: Down syndrome: orthopedic issues. Curr Opin Pediatr, 2008, 20: 30-36. [Medline] [CrossRef]

8) Peterlein CD, Schiel M, Timmesfeld N, et al.: [Characteristics in treatment of the hip in patients with Down syndrome]. Z Orthop Unfall, 2013, 151: 585-595 (In German). [Medline]

9) Fanter Nathan J: Down syndrome and orthopaedic problems. Hughston Health Alert, 2012, 24: 1-2.

10) Tanaka H: Orthopaedic complication of Down's syndrome. J Clin Rehabil, 2011, 20: 535-540 (In Japanese).

11) Merrick J, Ezra E, Josef B, et al.: Musculoskeletal problems in Down Syndrome European Paediatric Orthopaedic Society Survey: the Israeli sample. J Pediatr Orthop B, 2000, 9: 185-192. [Medline] [CrossRef]

12) Semine AA, Ertel AN, Goldberg MJ, et al.: Cervical-spine instability in children with Down syndrome (trisomy 21). J Bone Joint Surg Am, 1978, 60: 649-652. [Medline] [CrossRef]

13) Galli M, Cimolin V, Rigoldi C, et al.: The effects of low arched feet on foot rotation during gait in children with Down syndrome. J Intellect Disabil Res, 2014, 58: 758-764. [Medline] [CrossRef]

14) Yamamoto T, Sato M, Nagao S, et al.: Treatment for flexible flatfoot in Down's syndrome. J Jpn Ped Orthop Ass, 2006, 15: 252-255.

15) Morioka Y, Takei K, Yamamoto M: The current status in prescription of lower extremity orthotic in our hospital. Rigakuryouhou Rinshou Kenkyuu Kyouiku, 2017, 24: 40-42 (In Japanese).

16) Concolino D, Pasquzzi A, Capalbo G, et al.: Early detection of podiatric anomalies in children with Down syndrome. Acta Paediatr, 2006, 95: 17-20. [Medline] [CrossRef]

17) Diamond LS, Lynne D, Sigman B: Orthopedic disorders in patients with Down's syndrome. Orthop Clin North Am, 1981, 12: 57-71. [Medline]

18) Dinesh S, James R: Clinical: the management of flat feet in adults. GP: General Practitioner, 2005: 83-85.

19) Tawada S: Down syndrome and motor development. J Clin Rehabil, 2011, 20: 529-534.

20) Hunter Alasdair GW: Down syndrome: management of genetic syndromes. John Wiley \& Sons, 2005.

21) Galli M, Cimolin V, Pau M, et al.: Relationship between flat foot condition and gait pattern alterations in children with Down syndrome. J Intellect Disabil Res, 2014, 58: 269-276. [Medline] [CrossRef] 